Sādhanā Vol. 38, Part 4, August 2013, pp. 687-706. (C) Indian Academy of Sciences

\title{
Effects of vegetable-based cutting fluids on the wear in drilling
}

\section{BABUR OZCELIK $^{\mathrm{a}, *}$, EMEL KURAM $^{\mathrm{a}}$, ERHAN DEMIRBAS $^{\mathrm{b}}$ and EMRAH ŞIK ${ }^{\mathrm{b}}$}

\author{
${ }^{a}$ Department of Mechanical Engineering, Gebze Institute of Technology, \\ 41400 Gebze-Kocaeli, Turkey \\ ${ }^{\mathrm{b}}$ Department of Chemistry, Gebze Institute of Technology, \\ 41400 Gebze-Kocaeli, Turkey \\ e-mail: ozcelik@gyte.edu.tr
}

MS received 20 July 2011; revised 27 May 2013; accepted 19 August 2013

\begin{abstract}
This study focuses on both formulation of vegetable-based cutting fluids (VBCFs) and machining with these cutting fluids. For this purpose, characterizations of chemical and physical analyses of these formulated cutting fluids are carried out. In this study, performances of three VBCFs developed from crude sunflower oil, refined sunflower oil, refined canola oil and commercial semi-synthetic cutting fluid are compared in terms of tool wear, thrust force and surface roughness during drilling of AISI 304 austenitic stainless steel with HSSE tool. Experimental results show that canolabased cutting fluid gives the best performance due to its higher lubricant properties with respect to other cutting fluids at the constant cutting conditions (spindle speed of $750 \mathrm{rpm}$ and feed rate of $0.1 \mathrm{~mm} / \mathrm{rev}$ ).
\end{abstract}

Keywords. Drilling; tool wear; thrust force; surface roughness; vegetable-based cutting fluid.

\section{Introduction}

Tool wear influences hole quality (diameter and cylindricity), surface roughness and tool life. When tool wear reaches limiting value, the surface roughness of the hole deteriorates.

Drilling without cutting fluids generates some difficulties such as the removal of the chips from inside the holes and adheres to the chip on the drill. Cutting fluids increase the tool life and improve the efficiency of the production systems providing both cooling and lubricating the work surface. Higher surface finish quality and better dimensional accuracy are also obtained from cutting fluids (Soković \& Mijanović 2001). There are many types of cutting fluids widely used in metal cutting processes namely, straight oils, soluble oils, synthetic and semi synthetic fluids. Amongst them, bio-based cutting fluids have higher potential due to reducing of the occupational

*For correspondence 
health risks associated with petroleum-oil-based cutting fluids and higher biodegradability. The output is a healthier and cleaner in the work environment with less mist in the air and including a good lubricating ability as compared to others (John et al 2004).

Researches on drilling with vegetable-based cutting fluids (VBCFs) are limited. Therefore, it is necessary to develop and evaluate performance of VBCFs. Most of the studies about VBCFs have been focused on canola oil. The performance of canola-based cutting fluids was tried with various machining operations and compared with other commercial cutting fluids (Belluco \& De Chiffre 2001; De Chiffre \& Belluco 2002; Belluco \& De Chiffre 2004). In these studies, optimizations of four cutting fluids, two different VBCFs developed from refined sunflower oil and two commercial types (semi-synthetic and mineral) on the drilling were investigated for surface roughness during drilling of AISI 304 austenitic stainless steel using Taguchi experimental design (Ozcelik et al 2011). Kuram (2009) investigated effects of developed VBCFs and cutting parameters on drilling forces and surface roughness in the drilling. (Kuram et al 2010) used three different VBCFs developed from raw and refined sunflower oils and two commercial types (vegetable and mineral based) cutting fluids to determine effect of the cutting fluid types on the thrust force and surface roughness in the drilling.

Novelty of this work is to formulate vegetable based cutting fluids from sunflower and canola oils and evaluate their performance in terms of tool wear, thrust force and surface roughness at constant drilling conditions. The results are compared with the commercially available semisynthetic cutting fluid.

\section{Experimental design}

\subsection{Vegetable-based cutting fluid}

Vegetable oils consist of triacylglycerides (triglycerides) which are glycerol molecules with three long chain fatty acids attached at the hydroxyl groups via ester linkages. Long polar fatty acid chains provide high strength lubricant films. This film interacts strongly with metallic surfaces and reduces both friction and wear (Fox \& Stachowiak 2007).

In this study, VBCFs are prepared with both base oil and a mixture of surfactants in different ratios. Properties of surfactants used are shown in table 1 . The ability of a surfactant to form oil in water emulsion is defined in terms of hydrophilic-lyophilic balance (HLB) value which can be estimated by stirring into water and observing the mixture (Byers 2006).

Table 1. Properties of surfactants.

\begin{tabular}{lllrr}
\hline $\begin{array}{l}\text { Trade name } \\
\text { of surfactant }\end{array}$ & \multicolumn{1}{c}{ Surfactant composition } & Class & HLB & $\begin{array}{r}\text { Density } \\
\left(\mathrm{g} / \mathrm{cm}^{3}\right)\end{array}$ \\
\hline Peg 400 & Polyethylene glicol ester & Non-ionic & 9.7 & 1.13 \\
Tween 20 & Polyoxyethylene (20) Sorbitan monolaurate & Non-ionic & 16.7 & 1.10 \\
Tween 40 & Polyoxyethylene (40) Sorbitan monopalmitate & Non-ionic & 15.6 & 1.08 \\
Tween 60 & Polyoxyethylene (60) Sorbitan monostearate & Non-ionic & 14.9 & 1.04 \\
Tween 80 & Polyoxyethylene (80) Sorbitan monooleate & Non-ionic & 15.0 & 1.07 \\
Tween 85 & Polyoxyethylene sorbitan trioleat & Non-ionic & 11.0 & 1.02 \\
Span 80 & Sorbitan monooleate & Non-ionic & 4.3 & 0.99 \\
Castor oil & Castor oil oleate & Non-ionic & 8.4 & 1.01 \\
\hline
\end{tabular}


Three VBCFs are developed from crude (CSCF-II, two surfactants) and refined sunflower cutting oils (SCF-II, two surfactants). The other is prepared from refined canola oil using a mixture of two surfactants (CCF-II). The stability and efficiency of these emulsions are evaluated by varying the proportion of surfactants. Then the chemically stable emulsions are used as a metal cutting fluid in the machining experiments. Because so many chemical experiments are conducted to determine the most stable emulsions using various type of surfactants and varying the proportions of these surfactants, only the result of stable emulsions are presented in this study.

VBCFs are an oil-in-water emulsion type consisting of base oil, surfactant(s) and additives in the formula to meet the specifications such as resistance to bacterial growth, corrosion, foaming and wear (Dickinson 1992). The additive concentrations used are below 10\% w/w. An emulsion

Table 2. Characterization of VBCFs a) emulsion prepared with refined sunflower oil- Tween $85(20 \%)+$ Tween 20, b) refined canola oil- Tween 85 (20\%) + Peg 400 (3\%), and c) crude sunflower oil - Tween 85 $(20 \%)+$ Peg $400(3 \%)$.

\begin{tabular}{|c|c|c|c|c|c|c|c|}
\hline \multirow[b]{2}{*}{ Tween 20} & \multicolumn{7}{|c|}{ Surfactant proportion } \\
\hline & $2 \%$ & $3 \%$ & $4 \%$ & $9 \%$ & $12 \%$ & $15 \%$ & $20 \%$ \\
\hline $\mathrm{pH}$ & 5.3 & 5.4 & 5.4 & 5.5 & 5.5 & 5.6 & 5.7 \\
\hline Density $\left(\mathrm{g} / \mathrm{cm}^{3}\right)$ & 0.989 & 0.990 & 0.990 & 0.992 & 0.992 & 0.993 & 0.993 \\
\hline \multicolumn{8}{|l|}{ Viscosity (cp) } \\
\hline $30^{\circ}$ & 1.2 & 1.2 & 1.2 & 1.2 & 1.3 & 1.3 & 1.4 \\
\hline $40^{\circ}$ & 1.0 & 1.0 & 1.0 & 1.1 & 1.1 & 1.2 & 1.3 \\
\hline $50^{\circ}$ & 0.8 & 0.8 & 0.9 & 1.0 & 1.0 & 1.1 & 1.2 \\
\hline Surface tension $(\mathrm{dyn} / \mathrm{cm})$ & 25.28 & 25.20 & 24.92 & 24.56 & 24.41 & 24.28 & 23.89 \\
\hline \multicolumn{8}{|c|}{ a) } \\
\hline & \multicolumn{7}{|c|}{ Surfactant proportion } \\
\hline Peg 400 & $2 \%$ & $3 \%$ & $4 \%$ & $9 \%$ & $12 \%$ & $15 \%$ & $20 \%$ \\
\hline$\overline{\mathrm{pH}}$ & 7.05 & 7.05 & 6.80 & 6.75 & 6.70 & 6.70 & 6.65 \\
\hline Density $\left(\mathrm{g} / \mathrm{cm}^{3}\right)$ & 0.988 & 0.989 & 0.991 & 0.991 & 0.993 & 0.992 & 0.992 \\
\hline \multicolumn{8}{|l|}{ Viscosity $(\mathrm{cp})$} \\
\hline $30^{\circ}$ & 1.2 & 1.2 & 1.2 & 1.2 & 1.3 & 1.3 & 1.4 \\
\hline $40^{\circ}$ & 1.0 & 1.0 & 1.1 & 1.1 & 1.1 & 1.2 & 1.2 \\
\hline $50^{\circ}$ & 0.8 & 0.8 & 0.9 & 1.0 & 1.0 & 1.0 & 1.0 \\
\hline Surface tension $(\mathrm{dyn} / \mathrm{cm})$ & 24.05 & 23.99 & 23.89 & 23.69 & 23.55 & 23.21 & 23.05 \\
\hline \multicolumn{8}{|c|}{ b) } \\
\hline & \multicolumn{7}{|c|}{ Surfactant proportion } \\
\hline Peg 400 & $2 \%$ & $3 \%$ & $4 \%$ & $9 \%$ & $12 \%$ & $15 \%$ & $20 \%$ \\
\hline$\overline{\mathrm{pH}}$ & 6.90 & 6.74 & 6.65 & 6.64 & 6.68 & 6.56 & 6.51 \\
\hline Density $\left(\mathrm{g} / \mathrm{cm}^{3}\right)$ & 0.983 & 0.982 & 0.986 & 0.984 & 0.991 & 0.993 & 0.993 \\
\hline \multicolumn{8}{|l|}{ Viscosity $(\mathrm{cp})$} \\
\hline $30^{\circ}$ & 1.0 & 1.1 & 1.2 & 1.2 & 1.2 & 1.2 & 1.3 \\
\hline $40^{\circ}$ & 0.9 & 1.0 & 1.1 & 1.1 & 1.1 & 1.1 & 1.1 \\
\hline $50^{\circ}$ & 0.7 & 0.8 & 0.8 & 0.9 & 0.9 & 0.9 & 1.0 \\
\hline Surface tension $(\mathrm{dyn} / \mathrm{cm})$ & 24.62 & 25.29 & 24.66 & 24.84 & 24.67 & 24.22 & 24.07 \\
\hline
\end{tabular}

c) 
is a dispersion of one immiscible liquid into another, through the use of a chemical reagent that reduces the interfacial tension between the two liquids to achieve stability. Characterization of VBCFs is presented in table 2. Viscosity of a cutting fluid is one of the parameters to determine the effectiveness of cutting fluids. In the current study, viscosities of the emulsions are measured using a Brookfield LDV-E viscometer. The viscometer is calibrated with pure water. The viscosity results are presented in table 2 as a function of surfactant proportions and temperature. As the proportion of surfactant increases, the viscosity of fluids increases but decreases with increasing temperature. The lubricating properties of the cutting fluid increase with an increase in the proportion of surfactant.

As seen in figures 1 and 2, the peaks are overlapped each other and show that there is no chemical reaction between sunflower oil and Tween 20 occurred in the mixture but good dispersions are observed due to involving of van der Waals interactions between them. As contact angle decreases, the wettability of surfaces increases (table 3).

The stability of the emulsion is determined by analysing the droplet size distribution by Zetasizer Nano Series (Malvern Instruments). Its dilution produces very stable cutting fluid emulsion with oil droplets and the droplet sizes are varied in the range of 150-200 nm. Stabilities and visual appearances of VBCFs are shown in table 4 and figure 3 . Throughout this study, $8 \%$ of VBCF is mixed with $92 \%$ of water.

Refined sunflower emulsions prepared with Tween 85 (20\%) - Tween 20 (20\%) (table 4a), refined canola emulsions prepared with Tween 20 - Tween 85 (15-20\%), Tween 80 - Tween 85 (20\%), Tween 80 - Peg 400 (20\%), Tween 85 - Tween 80 (4, 9, 12\%), Tween 85 - Peg 400 (3, 4, 9, 12\%), Peg 400 - Tween 80 (15\%) and Peg 400 - Tween 85 (12, 15, 20\%) (table 4b) and

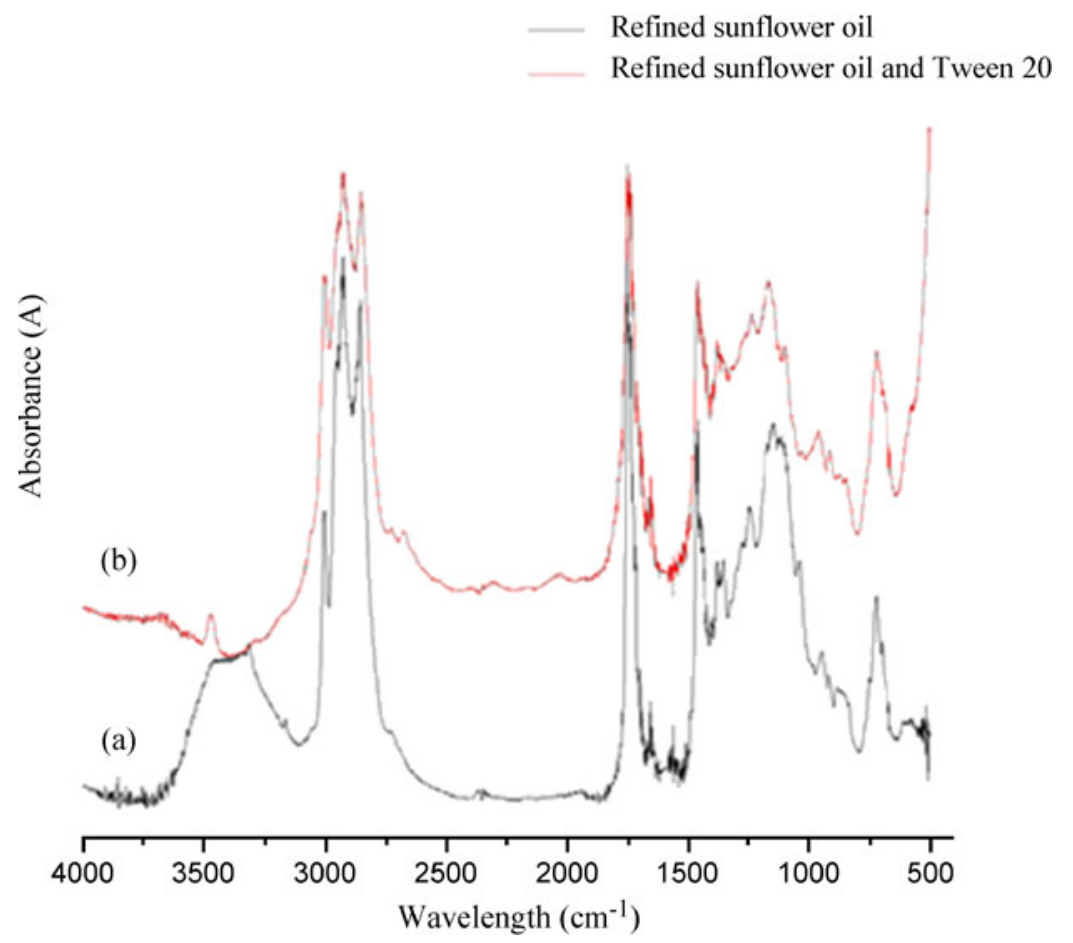

Figure 1. FTIR spectrum of (a) refined sunflower oil, and (b) refined sunflower oil-Tween 20. 


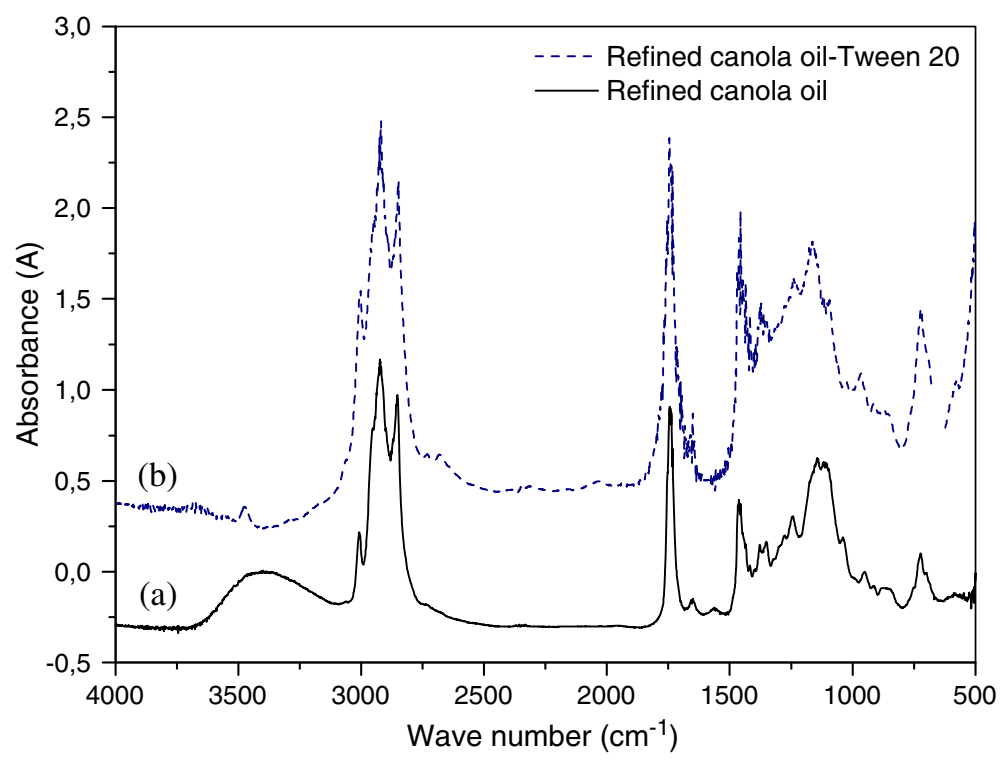

Figure 2. FTIR spectrum of (a) refined canola oil, and (b) refined canola oil-Tween 20.

crude sunflower emulsions prepared with Tween 20 - Tween 85 (20\%), Tween 80 - Tween 85 $(15,20 \%)$, Tween 85 - Tween $80(3,4,9,12,15 \%)$, Tween 85 - Peg $400(3,4,9 \%)$ and Peg 400 - Tween $85(4,9,12,15,20 \%)$ (table $4 c)$ give the best emulsion stabilities.

\subsection{Drilling conditions and experimental design}

The spindle speed, feed rate and drilling depth are considered as the machining parameters. The preliminary experiments are conducted in order to determine the value of spindle speed. Experimental results show that very high spindle speed causes the end of tool life because of catastrophic failure of the drill, but no significant progressive wear in cutting zone is observed previously. The drilling conditions for all the experiments are kept constant. The spindle speed, feed rate and drilling depth are $750 \mathrm{rpm}, 0.1 \mathrm{~mm} / \mathrm{rev}$ and $25 \mathrm{~mm}$, respectively. The drilling conditions are shown in table 5.

\subsection{Cutting fluids, workpiece materials and cutting tools}

Four cutting fluids, namely semi-synthetic commercial cutting fluid and 3 VBCFs developed from sunflower and canola oils in our laboratory are used in this study. A commercial semisynthetic cutting fluid is considered as reference oil. Flow rate for all cutting fluids is chosen as 10 1/min. Characterizations of VBCFs used in drilling experiments are shown in table 6.

The drilling experiments are carried out on a DECKEL MAHO DMU $60 \mathrm{P}$ five axis CNC milling machine equipped with a maximum spindle speed of $12000 \mathrm{rpm}$ and a $15 \mathrm{~kW}$ drive motor.

DIN 338 HSSE $130^{\circ}$ Silver Series drill ( $8 \mathrm{~mm}$ in diameter and $117 \mathrm{~mm}$ in length) is used as a cutting tool. In the experiments, a new drill is used for each cutting fluid. 
Table 3. Surface properties of refined canola, refined and crude sunflower and VBCF.

\begin{tabular}{lcc}
\hline Vegetable oils & Contact angle $(\theta)$ & Image of droplet of SBCF \\
\hline Refined sunflower oil & 29.15 \\
\hline
\end{tabular}

Refined sunflower oil-Tween 85 (20\%)

16.55

Crude sunflower oil

30.51

Crude sunflower oil-Tween 85 (20\%)

14.80
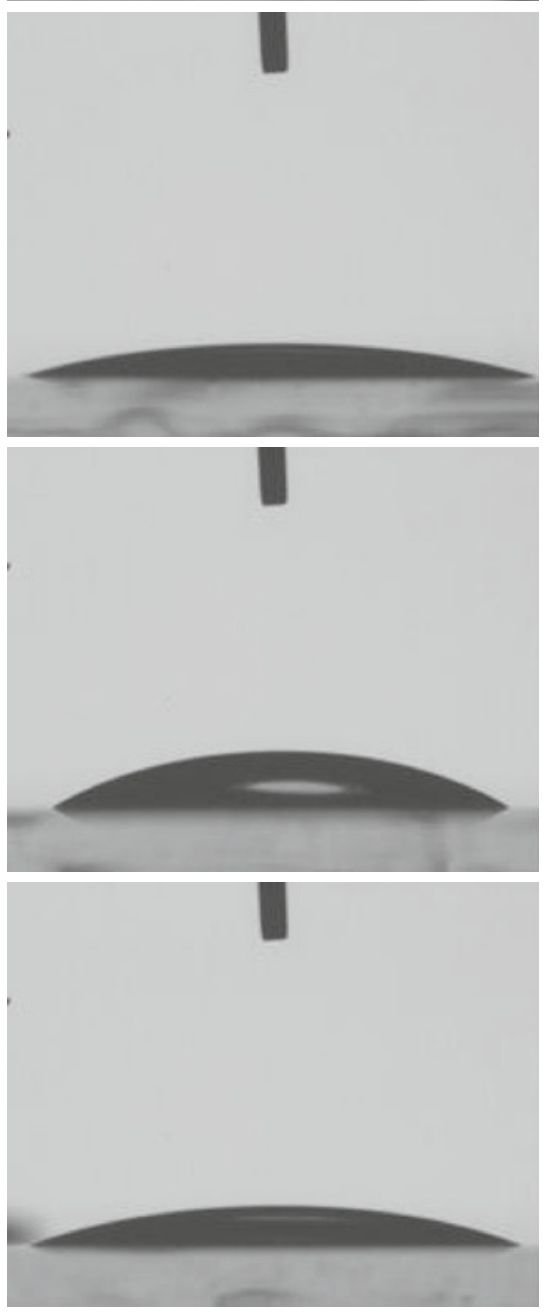
Table 3. continued.

\begin{tabular}{lcc}
\hline Vegetable oils & Contact angle $(\theta)$ & Image of droplet of SBCF \\
\hline Refined canola oil & 23.16 & \\
\hline
\end{tabular}

AISI 304 austenitic stainless steel with a Vickers hardness of 300 is used as a workpiece material. The dimension of workpiece is $160 \mathrm{~mm} \times 100 \mathrm{~mm} \times 30 \mathrm{~mm}$. The chemical composition of workpiece is given in table 7 .

\subsection{Tool wear measurement}

After the drilling, drill wear is measured at $50 \times$ magnification using an Olympus microscope. Flank wear of the drill is evaluated by measuring the wear in four different locations as shown in figure 4 (Lin \& Ting 1996). The wear of each cutting fluid is then computed as an average of four measurements.

The measured parameters are average flank wear $(V B)$, maximum flank wear (VBmax) at the drill corner and build-up edge formation. Due to the limited conditions, the experiment is halted after reaching of the $189^{\text {th }}$ drill hole or when any of the following criteria is met; $V B \geq 0.13 \mathrm{~mm}$, VBmax $\geq 0.3 \mathrm{~mm}$ or fracture or catastrophic failure.

\subsection{Thrust force measurement}

The thrust forces are measured with a Kistler 9257B type dynamometer. The dynamometer is mounted under the workpiece. Force data are saved on a personal computer, acquired via a DAQ Card and Dynoware software. The signal sampling frequency is selected as $1000 \mathrm{~Hz}$. 
Table 4. Emulsion stabilities of a) refined sunflower oil - Tween $85(20 \%)+$ Tween 20, b) refined canola oil - various two surfactants, and c) crude sunflower oil - various two surfactants (92\% water).

\begin{tabular}{lccccccc}
\hline \multirow{2}{*}{ Surfactant name } & \multicolumn{8}{c}{ Stability for the following surfactant proportions } \\
& $2 \%$ & $3 \%$ & $4 \%$ & $9 \%$ & $12 \%$ & $15 \%$ & $20 \%$ \\
\hline Tween 85 -Tween 20 & 2 & 2 & 3 & 3 & 3 & 3 & 4 \\
\hline
\end{tabular}

a)

\begin{tabular}{lccccccc}
\hline & \multicolumn{7}{c}{ Stability for the following surfactant proportions } \\
Surfactant name & $2 \%$ & $3 \%$ & $4 \%$ & $9 \%$ & $12 \%$ & $15 \%$ & $20 \%$ \\
\hline Tween 20-Tween 85 & 3 & 3 & 3 & 3 & 3 & 4 & 4 \\
Tween 80-Tween 85 & 1 & 1 & 1 & 2 & 2 & 3 & 4 \\
Tween 80-Peg 400 & 1 & 1 & 1 & 1 & 3 & 3 & 4 \\
Tween 85-Tween 80 & 3 & 3 & 4 & 4 & 4 & 3 & 3 \\
Tween 85-Peg 400 & 3 & 4 & 4 & 4 & 4 & 3 & 3 \\
Peg 400-Tween 80 & 2 & 2 & 3 & 3 & 3 & 4 & 2 \\
Peg 400-Tween 85 & 2 & 3 & 3 & 3 & 4 & 4 & 4 \\
\hline
\end{tabular}

b)

\begin{tabular}{lccccccc}
\hline & \multicolumn{7}{c}{ Stability for the following surfactant proportions } \\
Surfactant name & $2 \%$ & $3 \%$ & $4 \%$ & $9 \%$ & $12 \%$ & $15 \%$ & $20 \%$ \\
\hline Tween 20-Tween 85 & 3 & 3 & 3 & 3 & 3 & 3 & 4 \\
Tween 80-Tween 85 & 2 & 2 & 2 & 2 & 2 & 4 & 4 \\
Tween 85-Tween 80 & 3 & 4 & 4 & 4 & 4 & 4 & 3 \\
Tween 85-Peg 400 & 3 & 4 & 4 & 4 & 3 & 3 & 3 \\
Peg 400-Tween 85 & 3 & 3 & 4 & 4 & 4 & 4 & 4 \\
\hline
\end{tabular}

c)

4 Homogeneous, no separated, stable emulsion

3 Near to homogeneous

2 Partially phase separated, cream at surface

1 Completely phase separated

\subsection{Surface roughness measurement}

Surface roughness $(\mathrm{Ra})$ is measured with a Mitutoyo Surf Test 301. Cut-off length and number of sampling for the surface roughness measurements are selected as $0.8 \mathrm{~mm}$ and 3 , respectively. This measurement is repeated three times and the average value is used for the analysis. Measurement processes are made in parallel with drilled axis.

\section{Results and discussion}

In this study; tool wear, thrust force and surface roughness are measured in order to determine the performance of each vegetable cutting oils. Tool wears, thrust forces and surface roughness are measured at constant intervals, thrust force for every 9th hole; tool wear and surface roughness for every 27 th hole. The drilling process is stopped with every 27 th hole, and the drill is removed from the spindle in order to measure the drill wear. The comparative performance of each cutting fluids is evaluated by flank wear after drilling the last hole, and the results are computed by drilling of every 9 th hole for thrust force and drilling of every 27 th hole for the surface roughness. 


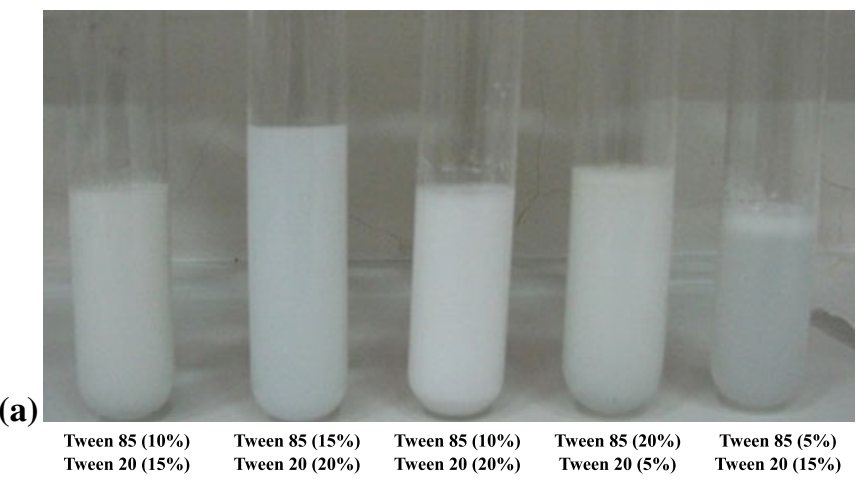

(b)

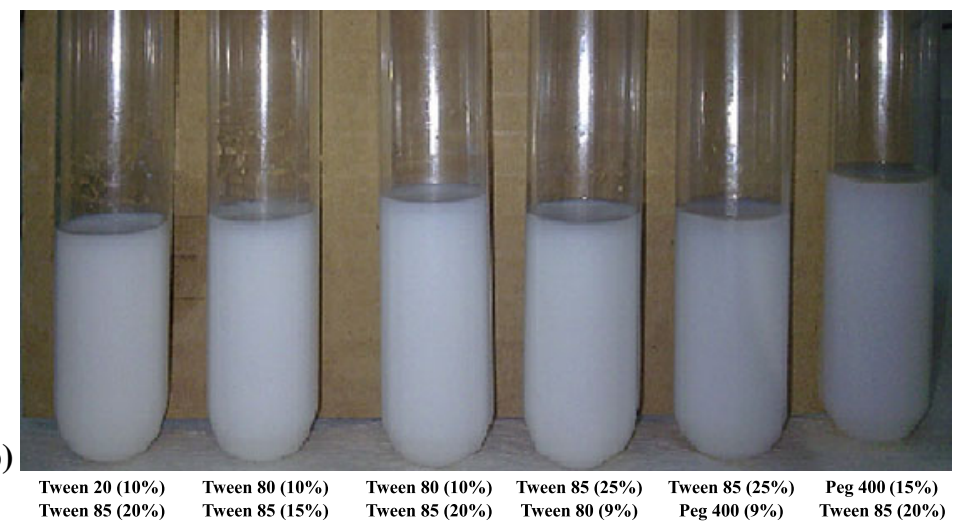

(c)

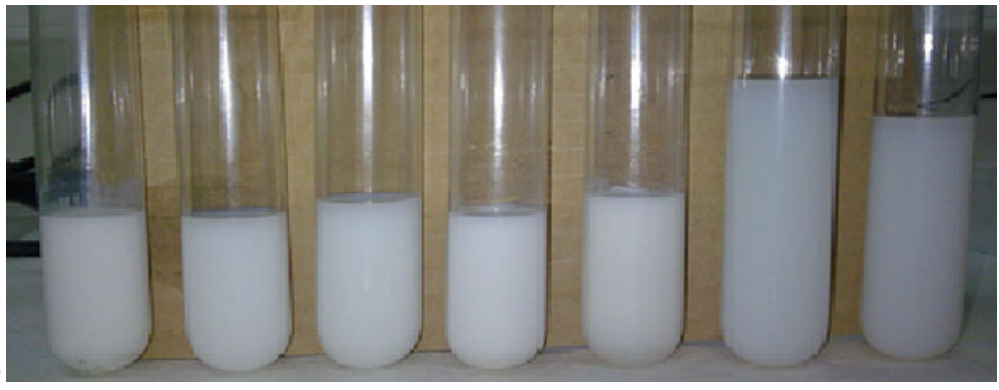

Tween $20(10 \%) \quad$ Tween $80(10 \%)$ Tween $85(25 \%)$ Tween $85(25 \%) \quad$ Peg $400(20 \%) \quad$ Peg $400(20 \%) \quad$ Peg $400(20 \%)$ Tween $85(20 \%)$ Tween $85(20 \%) \quad$ Tween $80(9 \%) \quad$ Peg $400(9 \%) \quad$ Tween $20(20 \%) \quad$ Tween $80(15 \%) \quad$ Tween $85(15 \%)$

Figure 3. Emulsion stabilities of VBCFs. (a) Various blends of refined sunflower oil and Tween 85-Tween 20 after 24 h. (b) Various blends of crude sunflower oil and different surfactants after 24 h. (c) Various blends of refined canola oil and different surfactants after $24 \mathrm{~h}$

Table 5. Drilling conditions. 
Table 6. Characterization of VBCFs.

\begin{tabular}{lcccccc}
\hline $\begin{array}{l}\text { Metal } \\
\text { cutting fluid }\end{array}$ & $\begin{array}{c}\mathrm{pH} \\
(\text { Emulsion 8\%) }\end{array}$ & $\begin{array}{c}\text { Density } \\
(\mathrm{g} / \mathrm{ml})\end{array}$ & $\begin{array}{c}\text { Viscosity } \\
40{ }^{\circ} \mathrm{C} \\
\left(\mathrm{mm}^{2} / \mathrm{s}\right)\end{array}$ & $\begin{array}{c}\text { Viscosity, } \\
40{ }^{\circ} \mathrm{C}\left(\mathrm{mm}^{2} / \mathrm{s}\right) \\
(\text { Emulsion } 8 \%)\end{array}$ & $\begin{array}{c}\text { Flash } \\
\text { point } \\
\left({ }^{\circ} \mathrm{C}\right)\end{array}$ & $\begin{array}{c}\text { Refractive } \\
\text { index }\end{array}$ \\
\hline SCF-II & 9.00 & 0.975 & 75.0 & 1.9 & 170 & 1.4750 \\
CCF-II & 8.94 & 0.960 & 77.0 & 2.7 & 200 & 1.4740 \\
CSCF-II & 9.28 & 0.960 & 65.0 & 1.4 & 205 & 1.4741 \\
SSF & 9.40 & 0.983 & 89.6 & 1.2 & 178 & 1.4785 \\
\hline
\end{tabular}

\subsection{Tool wear results}

Values of $V B, V B m a x$ and build-up edge $(B U E)$ are measured for each cutting fluid. The comparison of flank wears between cutting fluids is shown in figure 5 .

Drilled length is the cumulative depth of holes drilled during each experiment. From figure 5, it is observed that the average flank wear increases with increase in the number of holes drilled. The results of flank wear measurement confirm that all VBCFs are successful in reducing the flank wear. The lowest tool wear is recorded for CCF-II after the drilling 189 holes. To compare the average flank wear of cutting fluids, the last holes are taken into account. The average flank wear for each cutting fluid after drilling the last holes are shown in figure 6. Compared to the SSF; SCF-II, CCF-II and CSCF-II reduce the flank wear by approximately $40.00 \%, 48.57 \%$ and $23.81 \%$, respectively. In figure 5 , it is seen that the average flank wear of sunflower oil is found to be higher than that of canola oil. The reason may be related to the lubricant effect of canola oil which is most efficient when AISI 304 stainless steel is drilled. Lower flank wear of canola oil as compared to sunflower oil is also attributed to carbon chains in their structure. Canola and sunflower oils have different length of carbon chains and canola oil has three carbons more (Kuram et al 2013). It is known that longer carbon chain can bear with high cutting temperature and improve the surface protection. Moreover, higher viscosity of canola oil resists the flow, providing more efficient lubrication at the tool-chip interface. Efficient lubrication reduces the friction between the cutting tool and workpiece and removes the heat at the interface easily. Low friction reduced the tool wear (Rahim and Sasahara 2011) and lower tool wear of canola oil was attributed to the above. The experimental results show that the average value of flank wears for CCF-II decreases by $14.29 \%$ as compared to that for SCF-II. SCF-II is considered to perform better than CSCF-II in terms of tool wear. The average value of flank wears for SCF-II decreases by $21.25 \%$ as compared to that for CSCF-II.

The viscosity of CCF-II is higher than that of SCF-II and CSCF-II which reduces frictions between the drill and workpiece, thus removal of heat generated at the tool-workpiece interface

Table 7. The chemical composition of workpiece material.

\begin{tabular}{lcccccccc}
\hline & & \multicolumn{9}{c}{ AISI 304 (\% weight) } & & \\
$\mathrm{C}$ & $\mathrm{Si}$ & $\mathrm{Mn}$ & $\mathrm{P}$ & $\mathrm{S}$ & $\mathrm{Cr}$ & $\mathrm{Ni}$ & $\mathrm{Mo}$ & $\mathrm{Al}$ \\
\hline 0.0320 & 0.5800 & 1.9300 & 0.0300 & 0.0100 & 18.4100 & 7.7400 & 0.3730 & 0.0031 \\
$\mathrm{Cu}$ & $\mathrm{Co}$ & $\mathrm{Ti}$ & $\mathrm{Nb}$ & $\mathrm{V}$ & $\mathrm{W}$ & $\mathrm{Pb}$ & $\mathrm{Mg}$ & $\mathrm{B}$ \\
0.6600 & 0.1040 & 0.0054 & 0.0300 & 0.0650 & 0.0190 & $<0.0030$ & 0.0170 & 0.0017 \\
$\mathrm{Sn}$ & $\mathrm{Zn}$ & $\mathrm{As}$ & $\mathrm{Bi}$ & $\mathrm{Ca}$ & $\mathrm{Ce}$ & $\mathrm{Zr}$ & $\mathrm{La}$ & $\mathrm{Fe}$ \\
0.0110 & 0.0180 & 0.0140 & $<0.0020$ & 0.0006 & 0.0290 & 0.0075 & 0.0031 & 69.9000 \\
\hline
\end{tabular}




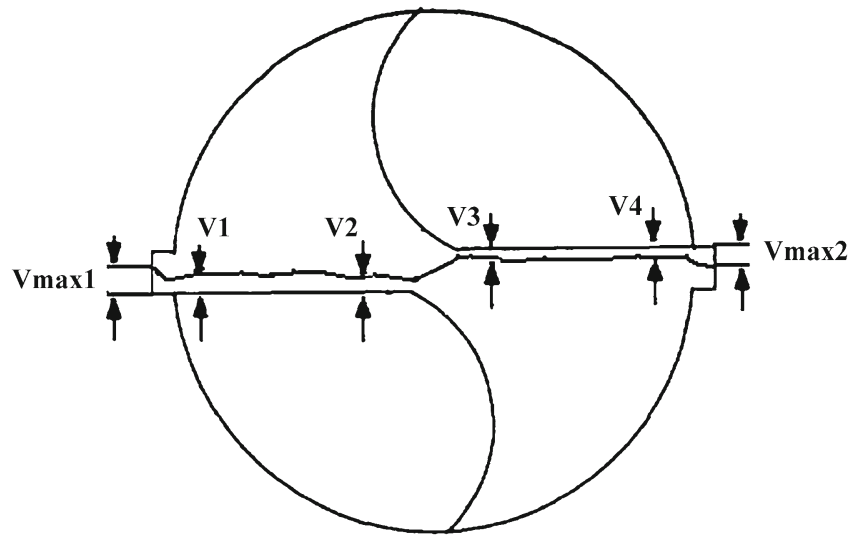

Average flank wear $(V B)=(\mathrm{V} 1+\mathrm{V} 2+\mathrm{V} 3+\mathrm{V} 4) / 4$

Maximum flank wear $(V B \max )=(\mathrm{V} \max 1+\mathrm{V} \max 2) / 2$

Figure 4. Measurement of drill wear.

gets easy. The higher the tool temperature, the faster the tool wears (Xavior \& Adithan 2009). Therefore, CCF-II generates the lowest tool wear.

The comparison of maximum flank wears between all types of cutting fluids when drilling AISI 304 is shown in figure 7. As seen in figure 7, VBmax increases with increase in the hole number. The lowest VBmax is achieved for CCF-II after drilling of 189 holes with respect to the rest of cutting fluids where the last holes are taken into account. VBmax of different cutting fluids after drilling the last hole is shown in figure 8. Compared to the SSF; SCF-II, CCF-II and

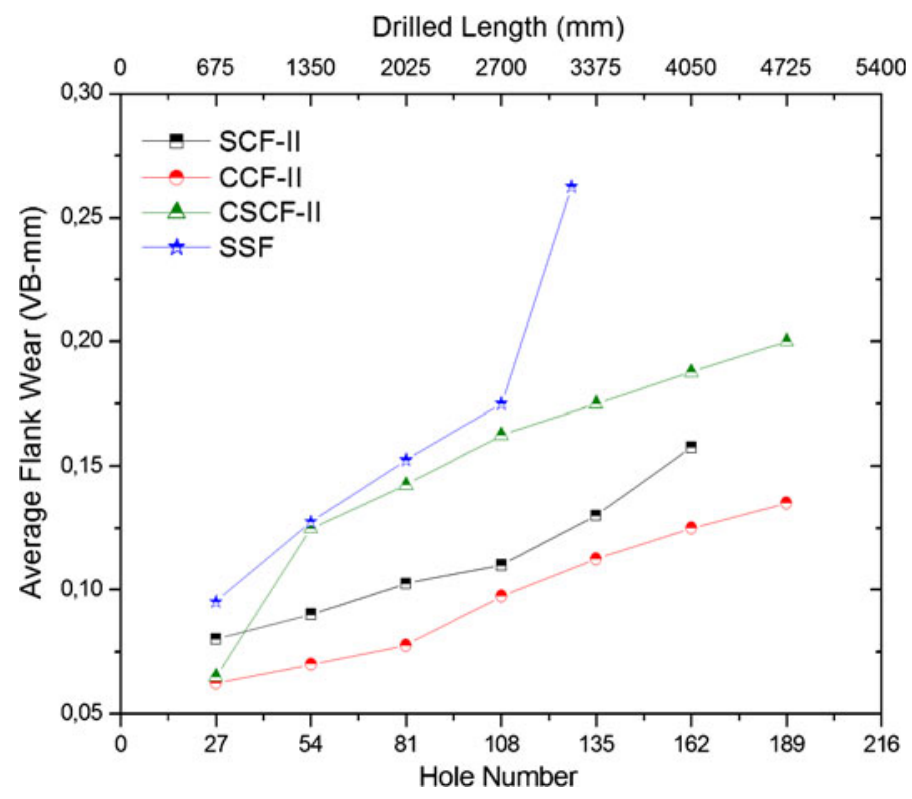

Figure 5. Effect of the cutting fluids on the average flank wears. 


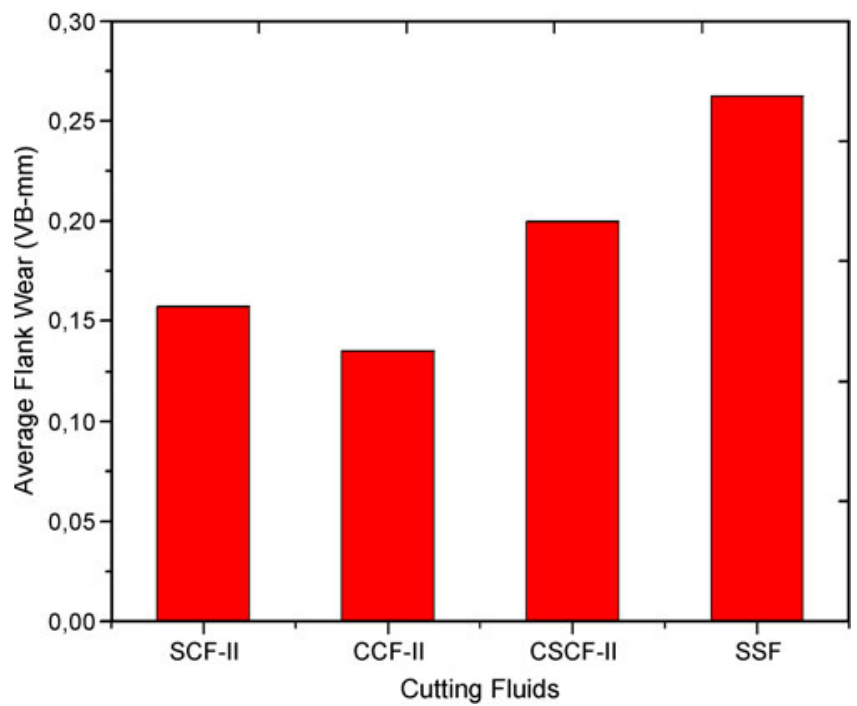

Figure 6. Average flank wear of different cutting fluids after drilling last holes.

CSCF-II reduce VBmax by approximately $18 \%, 32 \%$ and $20 \%$, respectively. In figure 7, value of VBmax for SCF-II is higher than that of CCF-II and SCF-II showing a better performance until 81 st hole is reached.

The comparison of BUE between the cutting fluids when drilling AISI 304 is shown in figure 9. The amount of BUE is changed mildly during the drilling but stable increases in the

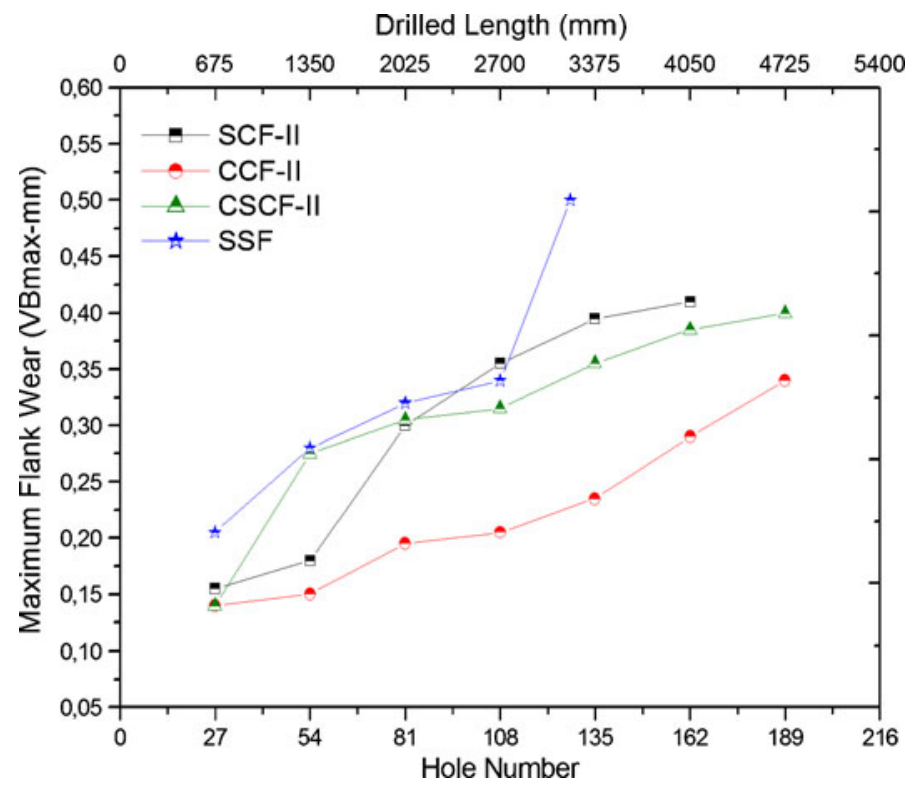

Figure 7. Effect of the cutting fluids on the maximum flank wears (spindle speed of $750 \mathrm{rpm}$ and feed rate of $0.1 \mathrm{~mm} / \mathrm{rev})$. 


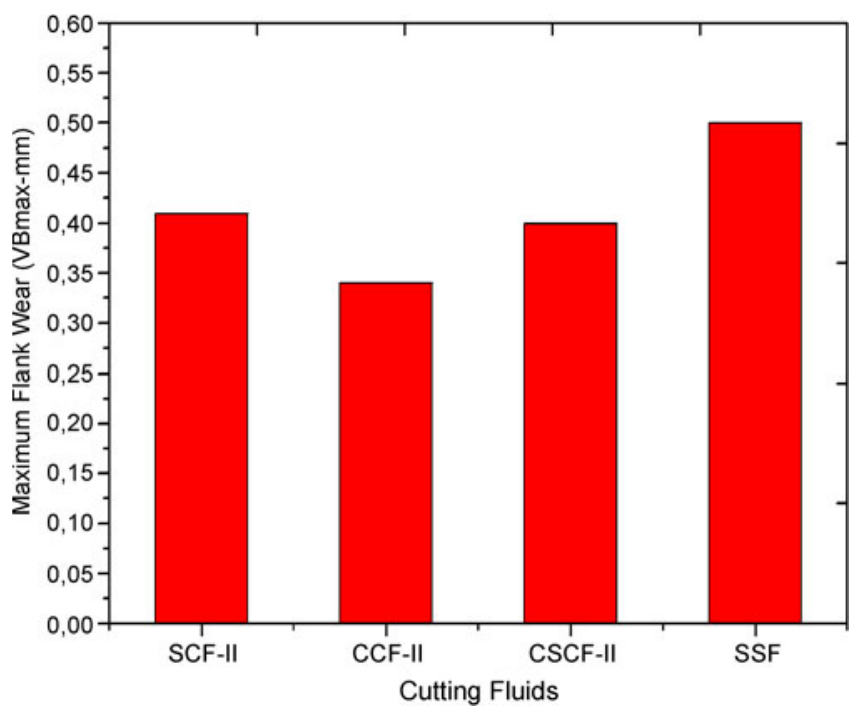

Figure 8. Maximum flank wear of different cutting fluids after drilling last holes.

BUE is not observed (figure 9). The lowest BUE is recorded for CCF-II after the drilling of 189th hole. The BUE formation is undesirable since it changes the diameter of hole, generates poor surface finish and tool chipping (Stephenson \& Agapiou 2006).

Types of tool wear for SCF-II after drilling of 54th, 81st, 108th and 162nd holes in figure 10, CCF-II after drilling of 27th, 81st and 189th holes in figure 11, CSCF-II after drilling of 54th,

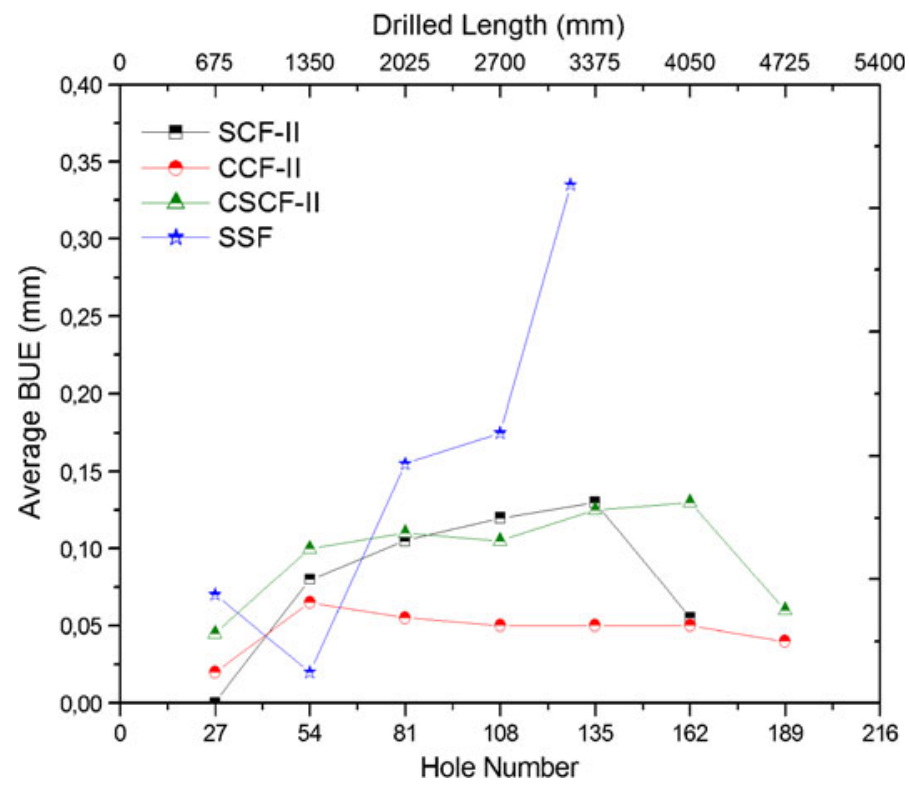

Figure 9. Effect of the cutting fluids on BUEs. 


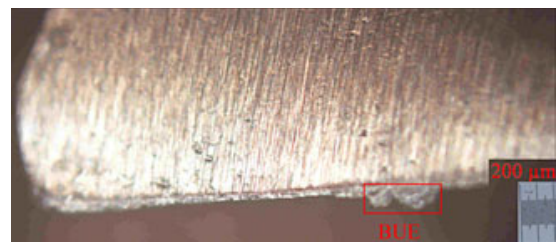

(a)

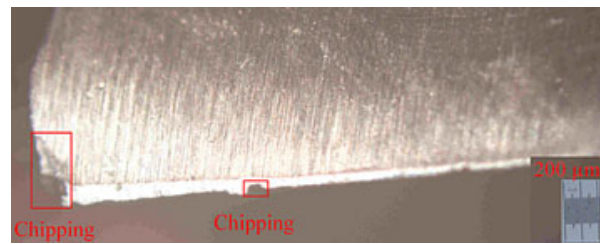

(c)

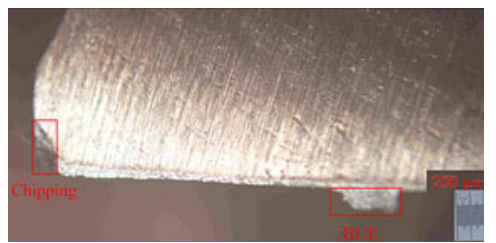

(b)

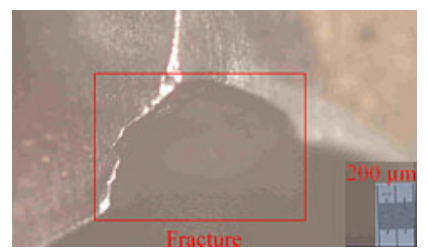

(d)

Figure 10. Tool wear types for SCF-II after drilling (a) 54; (b) 81; (c) 108, and (d) 162 holes.

108th, 135th and 162nd holes in figure 12 and SSF after drilling of 81st, 108th and 128th holes in figure 13, respectively are shown. Main wear mechanisms of the drills used in this study are flank wear, BUE and chipping. The width of drill flank wear increases according to the distance from the chisel edge due to the increase in cutting speed (in the chisel edge, cutting speed is close to zero) (Oh et al 2004). Chipping describes the breaking away of a small piece from the cutting edge of the tool. Two main causes of chipping are mechanical shock and thermal fatigue. Inconsistencies in the workpiece material composition or its structure also may induce chipping (Kalpakjian and Schmid 2001). When workpiece materials are hard the chipping occurs easily. Vibration due to excessive cutting forces also results in chipping which leads to poor surface finish, high flank wear and tool breakage (Stephenson \& Agapiou 2006).

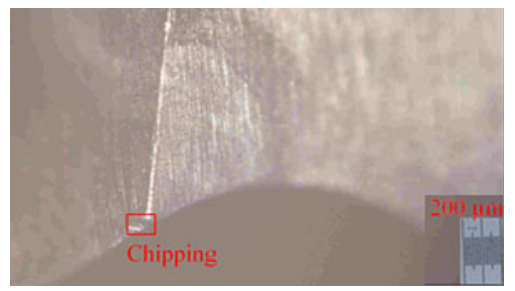

(a)

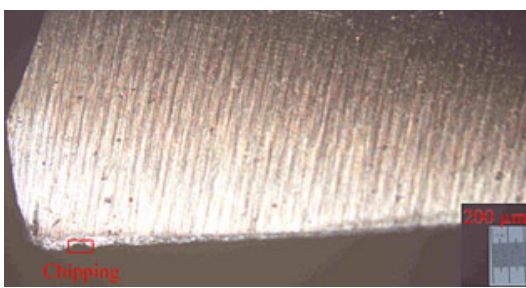

(b)

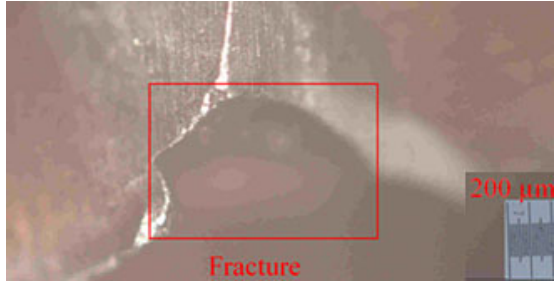

(c)

Figure 11. Tool wear types for CCF-II after drilling (a) 27; (b) 81, and (c) 189 holes. 


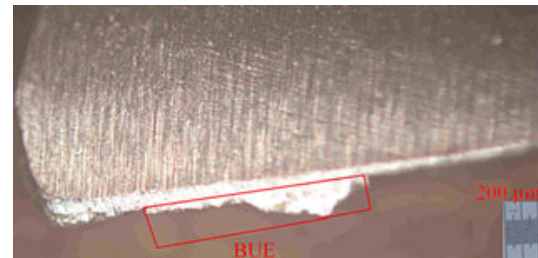

(a)

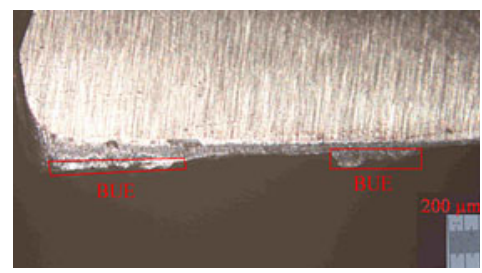

(c)

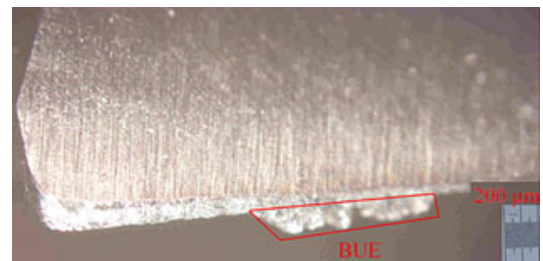

(b)

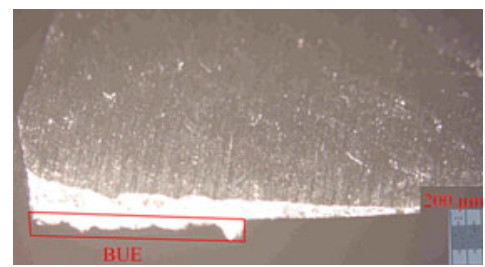

(d)

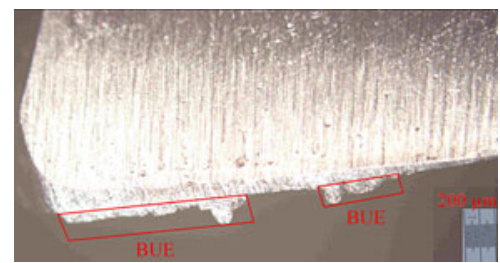

(e)

Figure 12. Tool wear types for CSCF-II after drilling (a) 54; (b) 108, (c)-(d) 135, and (e) 162 holes.

The drilling process for SSF is halted after 128th hole because of the tool failure. No drill breakage is observed, but tip of drill is rounded and deformed severely. Number of holes drilled by various cutting fluids is shown in figure 14 and CCF-II is found to be superior to the rest.

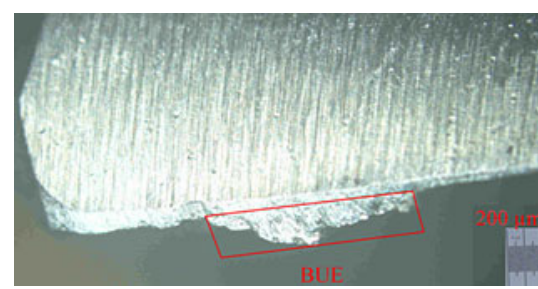

(a)

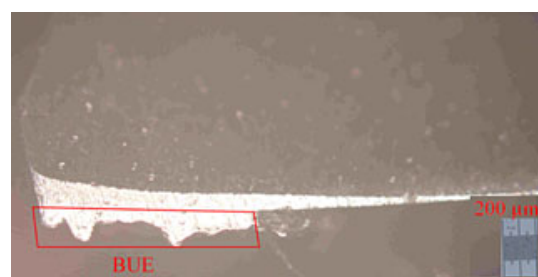

(b)

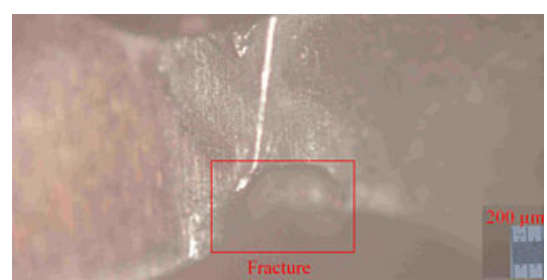

(c)

Figure 13. Tool wear types for SSF after drilling (a) 81; (b) 108, and (c) 128 holes. 


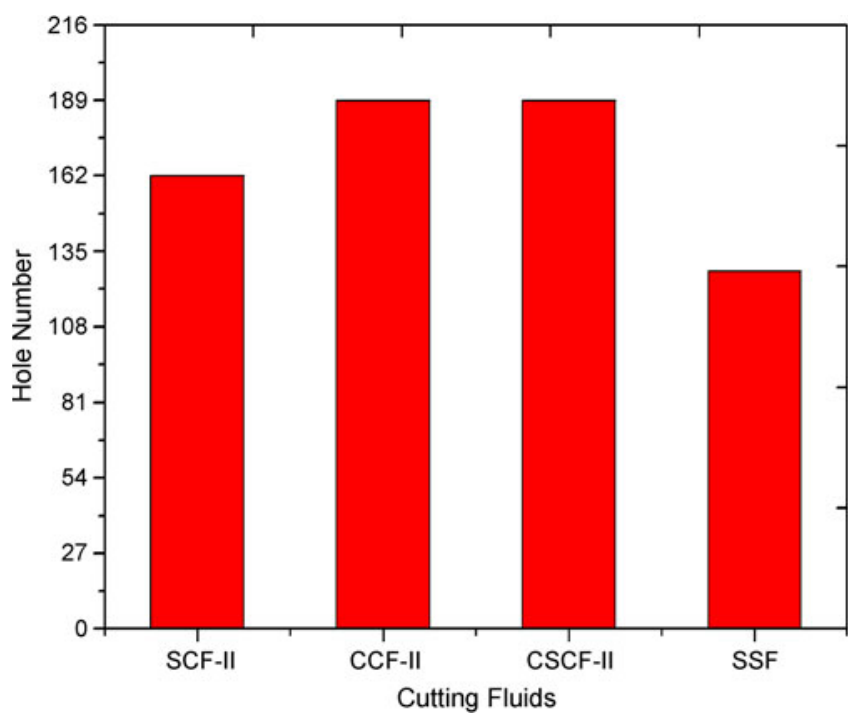

Figure 14. Number of holes drilled by various cutting fluids.

SSF produces the worst performance. In summary, drilling with SSF causes severe tool wear. However, the drill is still usable after drilling of 189th hole with CCF-II and CSCF-II. Lower tool wear of VBCFs as compared to SSF is attributed to fatty acid contents in VBCFs (Kuram et al 2013). Fatty acids can provide lubricant films with high strength and these films interact strongly with the contact surfaces. Therefore, wear and friction are decreased (Rahim and Sasahara 2011).

\subsection{Thrust force results}

Values of the thrust force are measured for each cutting fluid. Change in the thrust force as a function of hole number is shown in figure 15. The comparison of thrust forces between the cutting fluids is shown in figure 16. From figure 15 with the exception of CSCF-II, the thrust force measured by VBCFs is lower than that measured by the semi-synthetic cutting fluid. It is evident that generally the thrust force produced by CSCF-II increases as the number of holes drilled increased from 1 to 189 holes. Compared to the SSF; SCF-II and CCF-II reduce the thrust force by approximately $4.56 \%$ and $3.72 \%$, respectively (figure 16). In figure 16, the average thrust force of the canola oil is found to be higher than that of the sunflower oil. The experimental results show that the average thrust force value for SCF-II is almost as same as CCF-II. SCF-II generates lower thrust force than CSCF-II. The average value of thrust force for SCF-II decreases by $11.87 \%$ as compared to CSCF-II.

\subsection{Surface roughness results}

The surface roughness generated as a function of the hole number at the same conditions is shown in figure 17. The comparison of surface roughness between the cutting fluids is shown in figure 18. From figure 17, the surface roughness is not changed significantly when the number of hole is increased. Surface roughness of the holes drilled by the cutting fluids is changeable which 


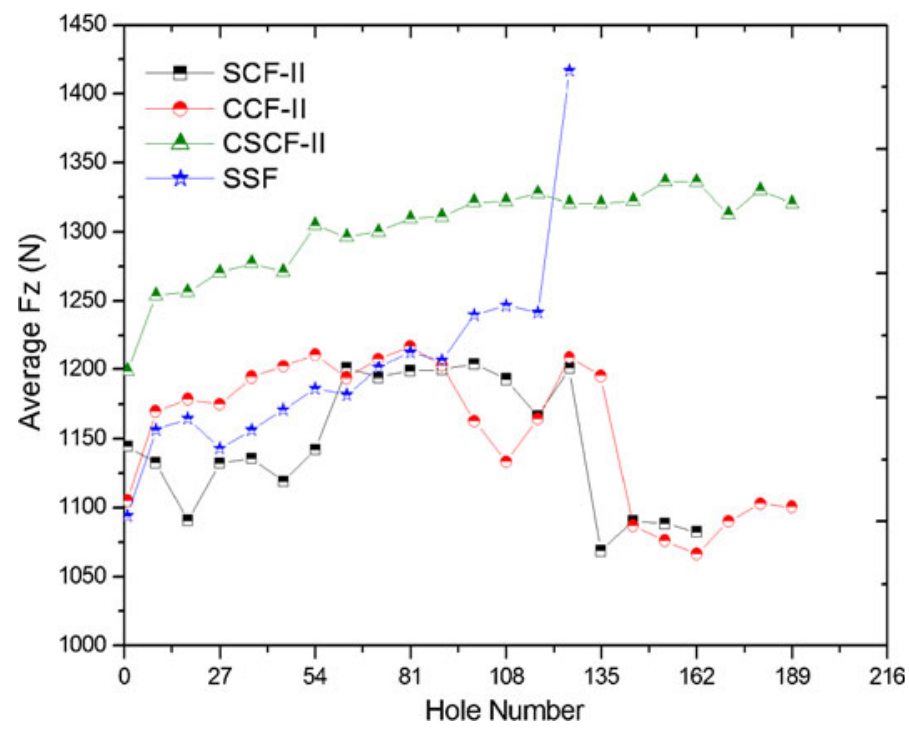

Figure 15. Effect of the cutting fluids on the average thrust forces (spindle speed of $750 \mathrm{rpm}$ and feed rate of $0.1 \mathrm{~mm} / \mathrm{rev})$.

is in agreement with the literature results (Chen \& Liao 2003; Nouari et al 2005; Danışman et al 2008). The fluctuation is due to increasing of force, temperature and chip clogging formation (Nouari et al 2005). The fluctuation of surface roughness values can also be explained by the ductility of AISI 304. This ductile nature increases the tendency of large and unstable BUE formation thus BUE causes fluctuation of surface roughness.

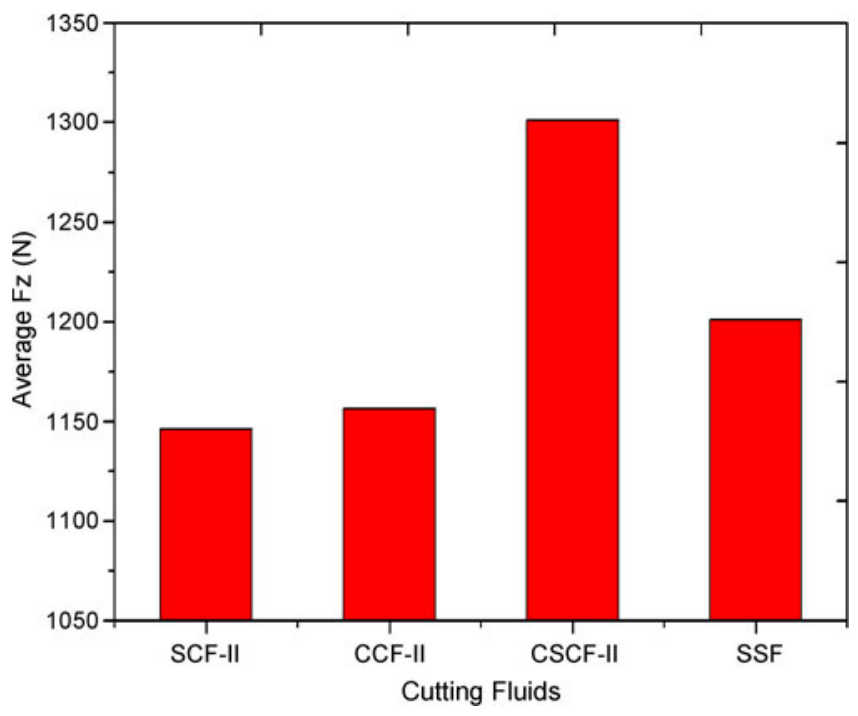

Figure 16. Average thrust force when drilling AISI 304 using cutting fluids (spindle speed of $750 \mathrm{rpm}$ and feed rate of $0.1 \mathrm{~mm} / \mathrm{rev}$ ). 


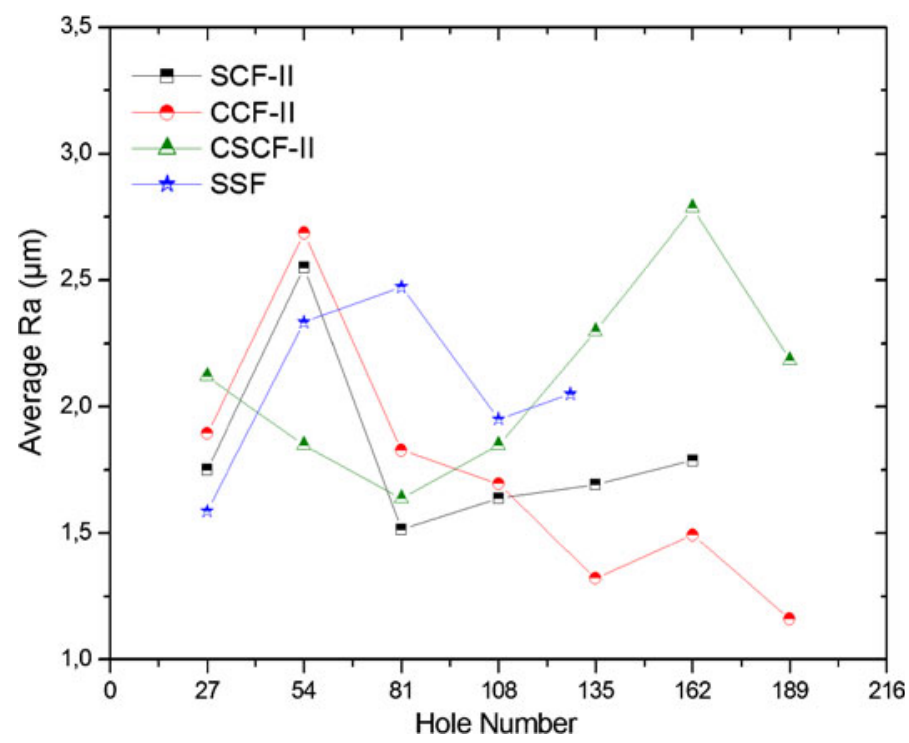

Figure 17. Effect of the cutting fluids on the average surface roughnesses.

Compared to the SSF; SCF-II and CCF-II reduce the surface roughness by approximately $12.39 \%$ and $17.03 \%$, respectively (figure 18). The average surface roughness of SCF-II in figure 18 is higher than that of CCF-II. The experimental results show that the average surface roughness value for CCF-II decreases by $5.29 \%$ as compared to SCF-II. SCF-II generates lower surface roughness than CSCF-II. The average value of surface roughness for SCF-II decreases by $13.38 \%$ as compared to that of CSCF-II.

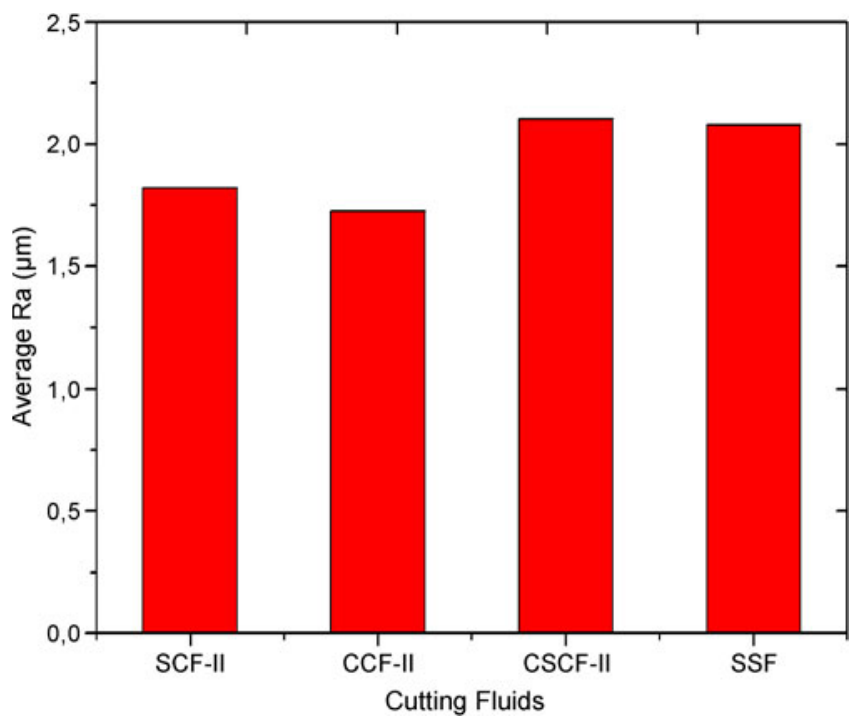

Figure 18. Average surface roughness when drilling AISI 304 using cutting fluids. 


\section{Conclusions}

Performances of the cutting fluids are evaluated by measurement of the tool wear, thrust force and surface roughness. Stable emulsions of VBCFs are obtained for Tween 85 (20\%)-Tween 20 (\%20) for SCF-II, Tween 20-Tween 85, Tween 80-Tween 85, Tween 80-Peg 400, Tween 85-Peg 400 for CCF-II and Tween 20-Tween 85, Tween 80-Tween 85, Tween 85-Peg 400 for CSCFII, respectively. The stable emulsions are important in the drilling experiments to evaluate the performance of developed VBCFs.

Main wear mechanisms of the drills used in this study are flank wear, BUE and chipping. The greater stresses and friction on the flank face induce flank wear and it is a dominant wear for the cutting fluids. The formation of BUE is due to the high chemical affinity between workpiece material and cutting tool. The presence of chipping may be due to the mechanical and thermal loading. CCF-II has the least flank wear as compared to rest of the cutting fluids. This could be owing to the fact that lower temperature occurs at the tool-workpiece interface when drilling is performed by CCF-II.

The minimum surface roughness value is obtained with CCF-II. The smallest thrust force is obtained with SCF-II. This observation indicates that SCF-II can reduce heat generation and friction between tool-chip interfaces. The thrust force and surface roughness of CSCF-II are found to be higher than that of SSF. CCF-II is the best cutting fluid for drilling of AISI 304 stainless steel. Semi-synthetic cutting fluid is not suitable for drilling of AISI 304 stainless steel due to the excessive wear and SSF shows a considerably poorer cutting performance.

\section{Acknowledgements}

The authors thank the Scientific and Technological Research Council of Turkey (TUBITAK) for supporting this project (project no: 107M164).

\section{References}

Belluco W and De Chiffre L 2001 Testing of vegetable-based cutting fluids by hole making operations. Lubrication Engineering 57: 12-16

Belluco W and De Chiffre L 2004 Performance evaluation of vegetable-based oils in drilling austenitic stainless steel. Journal of Materials Processing Technology 148: 171-176

Byers J P 2006 Metalworking fluids, 2nd ed., Boca Raton, Florida: Taylor \& Francis

Chen Y C and Liao Y S 2003 Study on wear mechanisms in drilling of Inconel 718 superalloy. Journal of Materials Processing Technology 140: 269-273

Danışman Ş, Savaş S and Topal E S 2008 Comparison of wear behaviours of cathodic arc TiN, TiAlN coated and uncoated twist drills under aggressive machining conditions. Tribology in Industry 30: 17-22

De Chiffre L and Belluco W 2002 Investigations of cutting fluid performance using different machining operations. Lubrication Engineering 58: 22-29

Dickinson E 1992 Interfacial interactions and the stability of oil-in-water emulsions. Pure and Applied Chemistry 64: 1721-1724

Fox N J and Stachowiak G W 2007 Vegetable oil-based lubricants-A review of oxidation. Tribology International 40: 1035-1046

John J, Bhattacharya M and Raynor P C 2004 Emulsions containing vegetable oils for cutting fluid application. Colloids and Surfaces A: Physicochem. Eng. Aspects 237: 141-150

Kalpakjian S and Schmid S R 2001 Manufacturing engineering and technology, 4th ed., New Jersey: Prentice Hall International 
Kuram E 2009 Investigation of vegetable-based cutting fluids performance in drilling, MSc thesis, Gebze Institute of Technology, Gebze

Kuram E, Ozcelik B, Demirbas E and Şık E 2010 Effects of the cutting fluid types and cutting parameters on surface roughness and thrust force, Proceedings of the World Congress on Engineering, London, United Kingdom, 1312-1315

Kuram E, Ozcelik B, Cetin M H, Demirbas E and Askin S 2013 Effects of blended vegetable-based cutting fluids with extreme pressure on tool wear and force components in turning of Al 7075-T6. Lubrication Science 25: $39-52$

Lin S C and Ting C J 1996 Drill wear monitoring using neural networks. Int. J. Machine Tools and Manufact. 36: 465-475

Nouari M, List G, Girot F and Géhin D 2005 Effect of machining parameters and coating on wear mechanisms in dry drilling of aluminium alloys. Int. J. Machine Tools and Manufact. 45: 1436-1442

Oh Y T, Kwon W T and Chu C N 2004 Drilling torque control using spindle motor current and its effect on tool wear. The Int. J. Advanced Manufact. Technol. 24: 327-334

Ozcelik B, Kuram E, Demirbas E and Ş1k E 2011 Optimization of surface roughness in drilling using vegetable based cutting oils developed from sunflower oil. Industrial Lubrication and Tribology 63: 271-276

Rahim E A and Sasahara H A 2011 A study of the effect of the palm oil as MQL lubricant on high speed drilling of titanium alloys. Tribology International 44: 309-317

Soković M and Mijanović K 2001 Ecological aspects of cutting fluids and its influence on quantifiable parameters of the cutting processes. Journal of Materials Processing Technology 109: 181-189

Stephenson D A and Agapiou J S 2006 Metal cutting theory and practice, 2nd ed., Boca Raton, Florida: Taylor \& Francis

Xavior M A and Adithan M 2009 Determining the influence of cutting fluids on tool wear and surface roughness during turning of AISI 304 austenitic stainless steel. Journal of Materials Processing Technology 209: 900-909 